\title{
PKM Bengkel Motor Rumahan
}

\author{
Jolis Joskar Anderias Djami $^{*}$, Melianus Toineno ${ }^{2}$ \\ ${ }^{1}$ fkip.j3p@gmail.com, ${ }^{2}$ melianustoineno@gmail.com \\ ${ }^{1}$ Program Pendidikan Jasmani Kesehatan dan Rekreasi \\ ${ }^{2}$ Program Studi Ilmu Hukum \\ ${ }^{1,2}$ Universitas Persatuan Guru 1945 NTT
}

Received: 1608 2019. Revised: 2108 2019. Accepted: 28082019

\begin{abstract}
This partnership or community service activity was implemented in "Bengkel Motor Nager" with the aim of assisting and realizing the knowledge and skills related to the construction of motorcycle engines, the working principle of motor machines, engine Fittings, electrical motorcycles, Unloading and tuning of machines, and on the motorcycle engines, which are specific focused on fuel measurements and compression ratios on the engine and camshaft; and the fulfilment of repair equipment to support the profession and business partners. The implementation method applied is to perform the Focus Group Discussion (FGD) with the partner; contact and elicit mechanical experts; Schedule of Trainings agreed together between the proposal, partners and trainers, the implementation of training, namely the introduction of theories and practices; procurement of repair equipment for partners. The results that have been achieved are the partners have the knowledge and skills needed by the partner, specifically everything related to motor machines and partners also have the repair equipment that supports the profession and business partners for the term long.
\end{abstract}

Keywords: motorcycle workshops, training, repair equipment, motorcycle mechanics

\begin{abstract}
Abstrak: Kegiatan pengabdian ini dilaksanakan di "Bengkel Motor Nager" dengan tujuan membantu dan mewujudkan pengetahuan dan keterampilan yang berkaitan dengan konstruksi mesin sepeda motor, prinsip kerja motor 4 tak, kelengkapan mesin, kelistrikan sepeda motor, bongkar pasang dan penyetelan mesin, dan hidupkan mesin sepeda motor, yang spesifik difokuskan pada pengukuran bahan bakar dan rasio kompresi pada mesin dan camshaft; dan pemenuhan perlengkapan bengkel demi menunjang profesi dan usaha mitra. Metode pelaksanaan yang diterapkan adalah melakukan Focus Gorup Discussion (FGD) bersama mitra; menghubungi dan mendatangkan ahli mekanik; pembuatan jadwal pelatihan yang disepakati bersama antara pengusul, mitra dan trainer, pelaksanaan pelatihan, yakni pemberian teori dan praktek; dan pengadaan peralatan bengkel bagi mitra. Hasil yang telah dicapai adalah mita telah memilki pengetahuan dan keterampilan yang dibutuhkan mitra, secara khusus segala hal yang berkaitan dengan mesin motor 4 tak dan mitra juga telah memiliki perlatan bengkel yang menunjang profesi dan usaha mitra untuk jangka panjang.
\end{abstract}

Kata kunci: bengkel motor, pelatihan, pengadaan, mekanik motor 


\section{ANALISIS SITUASI}

Keterampilan, keahlian, dan keuletan adalah faktor-faktor pendorong sesorang untuk mempertahankan hidup di era postmodern ini. Mempertahankan diri dan terus berkarir merupakan hal yang sangat penting dalam hidup agar bisa terus bereksistensi. Di Kota Kupang bengkel motor menjadi salah satu unit usaha yang menguntungkan karena banyak muda-mudi yang berkeinginan untuk memodifikasi motornya sesuai trend yang sedang berkembang. Jumlah total semua kendaraan yang baru dibeli tersebut masing-masing adalah 5024 kendaraan roda dua dan 660 kendaraan roda empat. Totalnya mencapai 5684 kendaraan (Colle, 2017).

Bengkel motor rumahan yang bernama "Nager" merupakan salah satu bengkel motor yang terletak di Jalan Banteng, Kelurahan Nunleu, Kecamatan Kota Raja, Kota Kupang, Nusa Tenggara Timur. Bengkel ini di kelola oleh seorang mekanik yang sekaligus berperan sebagai pemilik bengkel tersebut, dan dibantu oleh 4 orang pemuda putus sekolah. Pemilk bengkel "Nager" bernama Ronny Gousario. Roni menempuh pendidikan Menengah di STM Negeri Kupang, tetapi oleh karena kondisi ekonomi keluarga yang tidak memungkinkan, menyembabkan Ronny tidak dapat melanjutkan studi ke jenjang Strata. Ayah Roni bekerja sebagai kulih bangunan sedangkan ibunya sebagai ibu rumah tangga. Dalam kondisi seperti ini Ronny yang berprofesi sebagai pembalap motor jalanan, memilki jiwa juang yang tinggi untuk terus mempertahankan hidup. Dengan kemampuan mekanik ketika menempuh studi di Sekolah Menengah Kejuruan Negeri 1 Kota Kupang, Ronny kemudian mengumpulkan uang melalui balapan motor untuk membuka sebuah bengkel kecil di depan rumahnya. Kerja keras dan keuletannya untuk terus belajar secara otodidak, bengkel Ronny semakin disenangi oleh kalangan muda-mudi yang ingin mengikuti lomba balap. Bengkel motor ini tidak jual beli spare part motor, tetapi hanya menerima perbaikan motor dan cat motor oleh karena belum memiliki daya beli yang cukup.

Ronny sebagai pemilik dalam kesehariannya dibantu oleh 4 orang anggota teknisi pembantu mekanik yang merupakan anak putus sekolah juga, yang memiliki profesi sama seperti Ronny. Dalam melaksanakan pekerjaannya Ronny menerima pemasukan yang dapat dirinci sebagai berikut: 1). Jasa cat motor dikenakan biaya Rp. 1000.000, 2). Jasa perbaiki motor dikenakan biaya Rp.300.000-500.000 tergantung jenis kerusakannya, dan 3). Jasa modifikasi motor dikenakan biaya sebesar 2.000.000. Pemasukan seperti ini mengalami ketidakpastian tergantung pelanggan dan konsumen. Mitra melakukan berbagai cara untuk 
menjaga agar bengkel rumahannya tetap bereksistensi, seperti mempromosikannya melalui akun Facebook miliknya sendiri dan juga melalui teman-temannya.

Berkenaan dengan kondisi seperti ini, Roni mengharapkan agar pengetahuan dan skill mekaniknya perlu dikembangkan melalui pelatihan dan pendamping agar bisa memuaskan pelanggan demi berkompetisi dengan bengkel-bengkel yang lebih mapan di Kota Kupang. Kepuasan pelanggan atau konseumen yang dimaksud di sini adalah perasaan senang atau kecewa seseorang yang muncul setelah membandingkan antara persepsi atau kesannya terhadap kinerja atau hasil suatu produk dan harapan-harapannya [2]. Selain itu juga Roni berharap agar bisa memiliki perlatan bengkel yang lebih lengkap seperti Borcun, Bor Tangan, Gurinda, Travolas, dan kompresor listrik untuk mendukung pekerjaanya. Bahkan dapat memperbaiki halaman rumah agar kelihatan lebih menarik seperti bengkel pada umumnya.

\section{PERMASALAHAN MITRA}

Mitra sebagai anak putus sekolah yang memiliki semangat untuk bertahap hidup dan membantu orang tua, tetapi memiliki keterbatasan dalam menjalankan usaha.

1. Mitra memiliki keterbatasan dalam pengetahuan dan skill dalam kaitan dengan profesinya sebagai mekanik motor. Mitra hanya memiliki pengetahuan dan skill dasar saja oleh karena mitra dalam menempuh studi di STM mengambil jurusan Otomotif. Jadi, saat membuka usaha bengkel motor di depan rumah mitra, mitra terus belajar secara ototdidak. Oleh karena keterbatasan inilah mitra sering kehilangan pelanggan.

2. Mitra juga memiliki peralatan sebagai mekanik yang tidak lengkap dan jumlahnya juga sedikit. Hal ini menyebabkan mitra sering pergi meminjam alat-alat tertentu di tempat lain yang mana adalah kenalan mitra. Hal ini juga yang terkadang pelanggan atau konsumen merasa jenuh karena harus menunggu untuk beberapa menit.

\section{SOLUSI DAN TARGET}

Solusi yang dapat ditawarkan kepada mitra berkaitan dengan permasalahan yang sedang dihadapi adalah:

1. Mendatangkan mekanik motor yang professional atau ahli agar memberikan pelatihan dan pendampingan kepada mitra dalam hal pengembangan pengetahuan, keterampilan dan, keahlian mekanik demi pengembangan karir mitra dan kemajuan bidang usaha yang sedang digeluti dalam kaitannya dengan konstruksi mesin sepeda motor, prinsip 
kerja motor 4 tak, kelengkapan mesin, kelistrikan sepeda motor, bongkar pasang dan penyetelan, dan hidup mesin sepeda motor.

2. Mitra juga perlu dibantu dengan pengadaan alat-alat mekanik untuk pelaksanaan bidang usaha, seperti Borcun, Bor Tangan, Gurinda, Travolas, dan kompresor listrik. Semua ini dilakukan demi kepuasan konsumen. Tujuan pemasaran adalah memenuhi kebutuhan dan keinginan konsumen sehingga mencapai kepuasan (Kotler, 2010). Kepuasan konsumen adalah perasaan senang atau kecewa seseorang yang muncul setelah membandingkan antara persepsi atau kesannya terhadap kinerja atau hasil suatu produk dan harapan-harapannya.

Target yang telah dicapai dalam pelaksanaan Program Kemitraan Masyarakat ini antara laia: 1). Mitra telah memperoleh pengetahuan, keterampilan dan, keahlian mekanik demi pengembangan karir mitra dan kemajuan bidang usaha yang sedang digeluti dalam kaitannya dengan konstruksi mesin sepeda motor, prinsip kerja motor 2 tak dan 4 tak, kelengkapan mesin, kelistrikan sepeda motor, bongkar pasang dan penyetelan, dan hidup mesin sepeda motor; 2). Mitra memiliki alat-alat mekanik untuk pelaksanaan bidang usaha, seperti Borcun, Bor Tangan, Gurinda, Travolas, dan kompresor listrik. Semua ini dilakukan demi kepuasan konsumen.

\section{METODE PELAKSANAAN}

Metode pelaksanaan yang dapat diterapkan untuk dapat memberikan solusi terhadap permasalahan yang sedang dihadapi oleh mitra, yaitu:

1. Melakukan Focus Gorup Discussion (FGD) bersama mitra.

2. Melakukan survei berkaitan dengan ahli mekanik motor yang professional dari Honda dan Yamaha.

3. Menghubungi dan mendatangkan ahli mekanik motor yang dimaksud untuk pelatihan dan pendampingan terhadap mitra berkaitan dengan pengembangan pengetahuan, keterampilan dan skill mitra.

4. Pembuatan jadwal pelatihan yang disepakati bersama antara pengusul, mitra dan trainer.

5. Pelaksanaan pelatihan yang diawasi oleh pengusul.

6. Praktek lapangan yang didampingi oleh mitra dan diawasi oleh pengusul

7. Pengadaan alat-alat mekanik bagi mitra dalam bidang usaha yang sedang digeluti.

8. Evaluasi. 
Metode pelaksanaan ini dapat diterapkan dengan baik jikalau didukung sepenuhnya melalui prrtisipasi, keterlibatan dan peran aktif mitra dalam kaitan dengan pelaksanaan Program Kemitraan Masyarakat ini. Adapun partisipasi mitra, antara lain:

1. Mitra menyediakan tempat untuk pelatihan dan praktek lapangan.

2. Mitra mengungkapkan semua kendala dialami dalam pelatihan.

3. Mitra ikut mensurvei trainer dan alat-alat mekanik yang akan diadakan.

4. Mitra menyediakan waktu selama program PKM ini dilaksanakan.

Metode pelaksanaan ini juga sangat bergantung dengan pelaksanaan evaluasi program karena melalui evaluasilah peneliti dapat mengukur ketercapaian metode yang dipakai demi mencapai hasil yang berdayaguna dan bermanfaat bagi mitra. Evaluasi yang diterapkan dalam pelaksanaan Program PKM ini adalah evaluasi model CIPP.

1. Context evaluation: Dalam evaluasi konteks pengusul melakukan evaluasi terhadap kebutuhan mendasar dari mitra berkaitan dengan bengkel motor.

2. Input evaluation: Pengusul mengevaluasi kemampuan, pengetahuan, dan skill mitra dalam mengelola bengkel motor..

3. Process evaluation: Pengusul melakukan evaluasi terhadap kegiatan yang dilakukan, yaitu pelatihan dan pendampingan yang dilakukan oleh trainer. Dalam evaluasi ini juga perlu dipertimbangkan apakah program PKM ini berjalan sesuai jadwal, apakah material dipakai secara maksimal, dan apakah pelatihan dan pendampingan dipahami dan dapat diterapkan oleh mitra.

4. Product evaluation: Tahapan evaluasi ini untuk melihat apakah hasil yang dicapai sudah maksimal, dan apakah memiliki dampak yang signifikan.

\section{HASIL DAN LUARAN}

Pelatihan diberikan kepada mitra dalam kaitan dengan pengembangan pengetahun dan keterampilan mekanik motor. Materi yang diberikan dalam pelatihan adalah konstruksi mesin sepeda motor, prinsip kerja motor 4 tak, kelengkapan mesin, kelistrikan sepeda motor, bongkar pasang dan penyetelan, dan hidup mesin sepeda motor, yang spesifik difokuskan pada pengukuran bahan bakar dan rasio kompresi pada mesin dan camshaft. Pelatihan dimulai dengan materi tentang cara menggunakan buret pada mesin. Langkah-langkahnya sebagai beirkut:

1. Ketika membaca buret, mata harus tegak lurus dengan permukaan cairan. Bahkan ketebalan garis ukur juga mempengaruhi pembacaan. 
2. Untuk mengisi buret, menutup stopcock (keran) di bagian bawah dan menggunakan corong untuk menghindari terjadinya tumpahan.

3. Ketika mengisi buret sebaiknya menggunakan pipet transfer sekali pakai.

4. Sebelum titrasi, perlu diperhatikan kondisi buret dengan larutan titran dan memeriksa bahwa buret mengalir bebas.

5. Periksa ujung buret dari adanya gelembung udara. Untuk menghilangkan sebuah gelembung udara,dengan cara memukul sisi ujung buret sementara larutan mengalir.

Setelah pemberian materi buret, selanjutnya pelatihan yang berkaitan dengan rasio kompresi pada mesin. Dalam pelatihan ini lebih difokuskan kepada perbandingan antara volume silinder ketika piston berada di titik terendah dengan posisi piston pada titik paling atas. Semakin tinggi perbandingannya berarti udara yang terkompresi makin banyak, artinya bahan bakar yang terbakar bisa semakin banyak. Pada bagian ini mitra diajarkan cara menghitung rasio kompresi, awalnya kita harus tahu berapa kapasitas pada sebuah mesin yang akan kita hitung nanti (Tabel 1).

Tabel 1. Rumus Hitung

\begin{tabular}{|l|l|}
\hline \multicolumn{1}{|c|}{ Rumus Hitung cc Motor } & \multicolumn{1}{|c|}{ Rumus Hitung Rasio Kompresi } \\
\hline A x A x B X 3,14:4 & A : B \\
Dimana: & Dimana: \\
A : bore/ diameter piston & A : CC \\
B : stroke/langkah & B : hasil buret \\
$3,14 \quad:$ Nilai perbandingan antara keliling & Diketahui \\
dan diameter lingkaran & A : $121 \mathrm{cc}$ \\
$4 \quad:$ Angka baku & B : $12 \mathrm{cc}$ \\
Misalnya diketahui: & $121: 12=10.0833333: 1$ \\
A $: 54,5$ & Dibulatkan menjadi $10: 1$ \\
B $: 52$ & Jadi rasio kompresi adalah $10: 1$ \\
$54,5 \times 54,5 \times 52 \times 3,14: 4=121,245.605 \mathrm{cc}$ & \\
Dibulatkan menjadi $=121 \mathrm{cc}$ & \\
& \\
\hline
\end{tabular}

Mitra juga diberikan pelatihan berkaitan dengan dial camshaft. Pelatihan difokuskan kepada menemukan durasi, menemukan angka buka-tutup, menemukan angka LSA, menemukan overlap, mengetahui posisi klep terbuka ketika di berapa derajat, mengetahui posisi tinggi MAX klep terbuka (Gambar 1 \& 2). 
Tabel 2. Angka Ideal Durasi

- $\quad$ Durasi in $=$ angka terkecil $+180+$ angka terbesar

Durasi in $=30-40$ derajat

Durasi ex $=$ angka terbesar $+180+$ angka terkecil

Durasi ex $=60-80$ derajat

- Lift in dan ex $=9,0-10,0$

- Overlap =3,0-4,0

- LSA in dan LSA ex 102-105

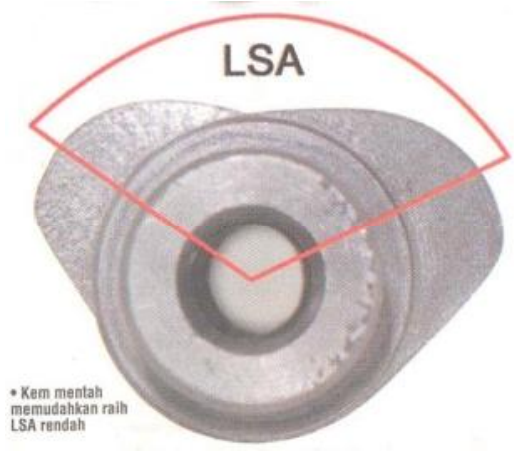

Gambar 1. LSA

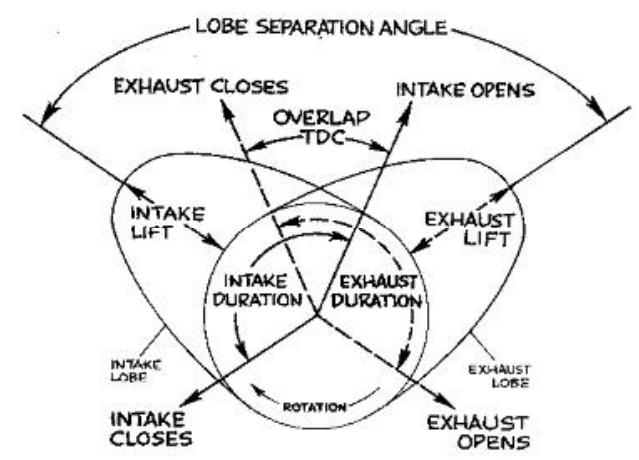

Gambar 2. Prinsip Kerja Mesin

Pelatihan juga difokuskan kepada prinsip kerja mesin motor 4 tak, yaitu: 1). intake (hisap), dimana piston bergerak dari TMA menuju TMB untuk menciptakan keadaan vacuum di dalam silinder mesin, lalu katup intake akan membuka untuk menghisap campuran bahan bakar dengan bensin yang sudah dikabutkan, sedangkan katup exhaust tertutup; 2). Kompresi, Langkah kompresi dimulai ketika piston mulai bergerak ke TMA dari TMB. Ketika langkah kompresi, katup intake akan menutup sehingga campuran udara-bahan bakar terperangkap di dalam silinder dan terkompresi (termampatkan) hingga sesaat sebelum TMA, busi akan menyala dan meledakkan campuran udara-bahan bakar. Penekanan atau pemampatan campuran udara-bahan bakar sangatlah penting karena akan menghasilkan daya maksimal ketika langkah tenaga (power); 3). Tenaga, Tenaga pukulan pukulan dimulai ketika campuran udara-bahan bakar dikompresi dan dinyalakan di ruang bakar. Busi yang terletak di kepala silinder akan menciptakan percikan bunga api untuk membakar campuran udara-bahan bakar. Dalam waktu yang singkat, campuran udara-bahan bakar mengembang dan meledak sehingga menciptakan tekanan yang sangat tinggi terhadap piston. Tekanan ini lah yang mendorong piston ke bawah menuju TMB dan memutar poros engkol serta menggerakkan roda kendaraan; dan 4). Buang, katup buang terbuka dan piston naik menuju TMA mendorong sebagian gas buang yang tersisa di dalam silinder. Ketika piston mulai mendekati TMA maka katup buang akan menutup dan katup intake akan membuka. Pembukaan katup 
intake ini adalah awal siklus baru. Siklus ini akan terjadi di silinder mesin dan akan berulang selama mesin berjalan.

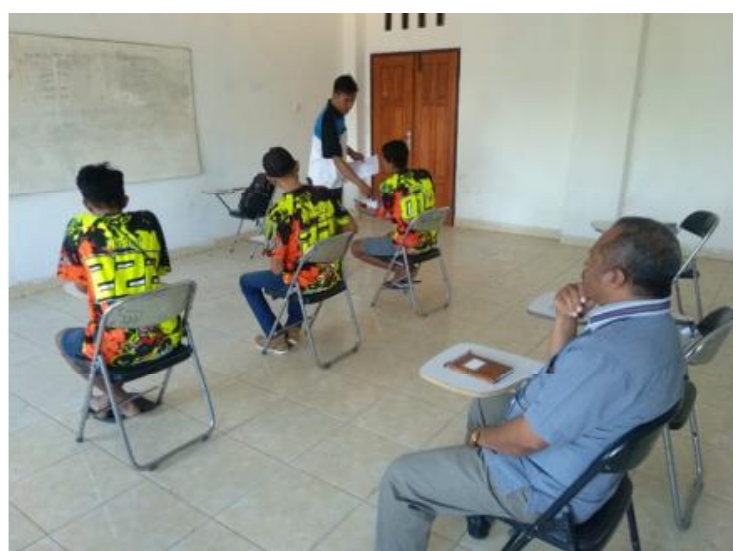

Gambar 1. Pemberian Teori

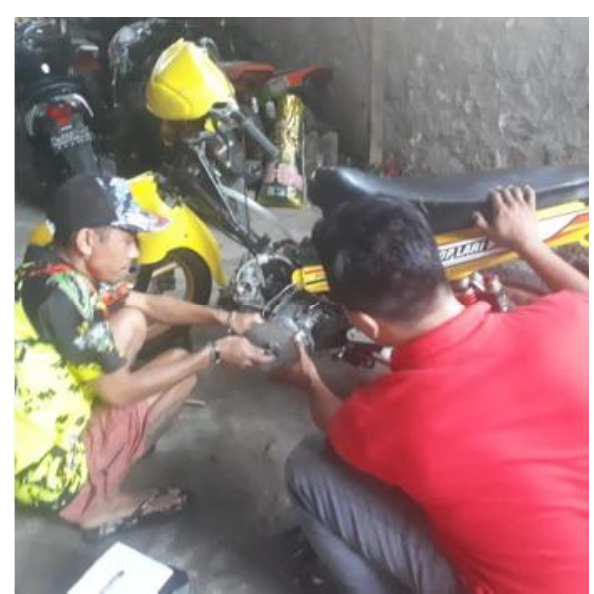

Gambar 2. Praktek Lapangan

\section{SIMPULAN}

Kegiatan Program Kemitraan Masyarakat telah berhasil dilaksanakan dan mencapai hasil 70\%, hasil capaian ini antara lain: 1). Pengelola Bengkel Motor "Nager" dan 4 orang teknisi yang membantunya telah memiliki pengetahuan dan keterampilan yang berkaitan dengan konstruksi mesin sepeda motor, prinsip kerja motor 4 tak, kelengkapan mesin, kelistrikan sepeda motor, bongkar pasang dan penyetelan, dan hidup mesin sepeda motor, yang spesifik difokuskan pada pengukuran bahan bakar dan rasio kompresi pada mesin dan camshaft; 2). Mitra telah diperlengkapi dengan perlatan bengkel demi menunjang profesi dan usahanya.

\section{DAFTAR RUJUKAN}

Colle, Gaudiano, (2017). Lebih Dari 5000 Kendaraan Bermotor Dibeli Oleh Warga Kota Kupang, diakses 21 Oktober 2018 dari http://kupang.tribunnews.com/2017/07/06/lebihdari-5000-kendaraan-bermotor-dibeli-oleh-warga-kota-kupang.

Kotler Philip (2010), Manajemen Pemasaran di Indonesia: Analisis, Perancanaan, Implementasi dan Pengendalian. Salemba Empat: Jakarta. 